\title{
Effects of Weaning and Sex of Calf on Postpartum Resumption of Reproduction in Mother Buffaloes
}

\author{
K.J. Kantharaja, A.K.S. Tomar, O.R. Nataraju* and B.T. Naveen Kumar \\ Division of Livestock Production Management, Indian Veterinary Research Institute, \\ Izatnagar, Bareilly - 243 122, India \\ *Corresponding author
}

\begin{abstract}
A B S T R A C T

\begin{tabular}{|c|}
\hline Keywords \\
\hline $\begin{array}{l}\text { Murrah buffalo } \\
\text { calves, Suckling, } \\
\text { Weaning, Service } \\
\text { period }\end{array}$ \\
\hline Article Info \\
\hline $\begin{array}{l}\text { Accepted: } \\
07 \text { April } 2018 \\
\text { Available Online: } \\
10 \text { May } 2018\end{array}$ \\
\hline
\end{tabular}

Thirteen newly born Murrah buffalo calves were utilized for the experiment and were randomly allocated to suckling and weaned groups. The allocation resulted in 7 suckling calves as well as 6 calves under weaning system of management. The overall least squares' means (LSM's) for LWB's of Murrah buffalo calves at birth, 1, 2, 3, 4, 5, 6, 7, 8, 9, 10, 11, $12,13,14,15,16,17,18,19,20,21,22,23,24,25,26,27,28,29,30$ and 31 weeks of age were $30.87 \pm 1.13,37.81 \pm 2.37,41.50 \pm 2.23,44.02 \pm 2.29,46.65$. $\pm 2.35,49.31 \pm 2.57$, $52.54 \pm 2.85,54.46 \pm 2.82,58.65 \pm 3.10,63.56 \pm 3.02,67.73 \pm 3.19,71.35 \pm 3.46,76.53 \pm 3.53$, $79.16 \pm 3.31,84.04 \pm 3.75,89.59 \pm 3.89,93.49 \pm 3.83,99.25 \pm 4.42,103.20 \pm 4.48,108.22 \pm 5.29$, $113.45 \pm 5.34, \quad 118.12 \pm 5.25, \quad 123.41 \pm 4.89, \quad 127.53 \pm 4.68, \quad 127.20 \pm 4.69, \quad 134.41 \pm 5.37$, $145.18 \pm 3.84,149.59 \pm 3.85,152.95 \pm 3.73,164.42 \pm 5.46$ and $168.48 \pm 5.46 \mathrm{~kg}$, respectively. The overall mean for service period in dams of Murrah buffalo calves was $95.00 \pm 39.11 \mathrm{~d}$. Dams of suckling calves had more mean for service period than dams of weaned calves and it was found to be almost double of that of dams of female calves. The service period was more in dams of later parities, in general. Considering the fertility response of weaning induced estrous cycles, the results of this study further reaffirm the fact that weaning effect can enhance the conception rates and reduce service period
\end{abstract}

\section{Introduction}

Buffaloes, with enormous genetic variability (Sadana et al., 2002), play important roles in livestock economy of developing countries by contributing significantly to milk, meat, hides and skins along with drought power. In developing countries like India, after birth, the calf is allowed to follow its mother, with suckling continuing until 1-2 years old because the farmer has no way to wean the calves. That may be one of the reasons for long calving intervals in buffaloes as it has been proven that suckling causes delayed postpartum resumption of ovarian activity (Lamb et al., 1997) and Weaning calves during the first week after calving dramatically reduced the time from calving to the onset of ovarian activity (Moore and Campos, 1983; Wells et al., 1985) due to hormonal changes that stimulate estrus (Short et al., 1990, Lamb et al., 1999).

However, the effect of weaning calves beyond the first week after calving results in varied responses (Alberio et al., 1984; Lishman and 
Harwin, 1985). Beside hormonal changes, buffaloes must have energy to support all body activities, but some functions have a higher priority for energy use than others. Buffaloes can only direct energy toward resuming the estrous cycle after calving if energy intake exceeds the combined requirements for maintenance, growth and lactation (Rae et al., 1993). This is why body condition is strongly related to the length of the postpartum anestrous period in beef cattle (Laster 1973, Houghton et al., 1990). Since body condition influences reproductive performance, early weaning or restricted suckling can be utilized to improve the chance that a buffalo is in a proper body condition and thus reproduction post calving.

However, the above mentioned effects of early weaning on reproduction have been so far shown from studies on cattle. Therefore, the present study was undertaken to test the hypothesis that early weaning of the calves could also shorten the postpartum interval in the mother buffalo and service period to enhance the reproductive performance of buffaloes.

\section{Materials and Methods}

The study was carried out at Calf Unit of Cattle and Buffalo Farm of Livestock Production and Management Section, Indian Veterinary Research Institute (IVRI), Izatnagar, Bareilly, Uttar Pradesh (India). Twenty five newly born Murrah buffalo calves were utilized for the experiment. These calves were divided in to two experimental groups. Group 1 (control): $(n=12)$ calves were allowed to suck their mothers as long as they could and follow the traditional practice. Group 2 (weaning): $(\mathrm{n}=12)$ day old weaning was followed for weaning and this group was kept under artificial nursing. Each calf was fed with colostrum of its own dam within few hours after birth and twice daily for three days at the rate of $10 \%$ of live body weight. Later, it was kept under hand feeding followed by pail feeding till 71 days of age. Along with milk feeding, calves were provided free access to calf starter during morning and night hours. Succulent green fodder and roughages were also made available to these calves as early as possible after initial learning on ad lib basis.

The animals which were in suckling group were allowed to suckle their dams all along the lactation period along with provision for calf starter and ad lib green fodder. In both groups, the mother buffaloes were allowed to eat fodder and concentrate as farm management standard protocol. The mother buffaloes were observed for standing oestrus twice daily since the start of experiment until 210 days postpartum. Data were subjected to analyses of variance (ANOVA) for a $2 \times 2$ factorial model with interactions using the General Linear Model (GLM) of Minitab 16. Pair-wise comparisons of means were done using the Tukey test.

\section{Results and Discussion}

The first heat and service period of dams after calving of both the sex of calve and weaned and suckled calve were presented in figure 1 and 2 , respectively. There was significant $(p<0.01)$ was observed between the mother of suckled and weaned calves and between the male and female calves in expression of first heat after calving and service period in the buffalo cows. The value for mean of days to express first heat after calving was more for dams of suckling calves (99.25 \pm 9.15 days) as compared to that in dams of weaned calves (62.50 \pm 1.50 days).

Dams of male calves had more days between calving to expression of first heat after calving than the dams of female calves. In the present study, postpartum interval to resumption of first estrus $(62.50 \pm 1.50$ vs. $99.25 \pm 9.15$ 
days) was shorter for weaned buffaloes than suckling buffaloes. This is in agreement with the report of Short et al., (1972) wherein it was reported that weaning calves at birth resulted in a shortened interval from calving to first estrus. These results are consistent with the reports of Perera (2011) who reported that dairy buffaloes managed with no suckling resume oestrus cyclicity by $30-60$ days after calving. This is further supported by the reports of Bellows et al., (1974) wherein they reported that cows suckled ad libitum have longer intervals to first estrous and/or ovulation than cows that have been weaned.

Fig.1 First heat after calving and service period of dam of male female buffalo calves

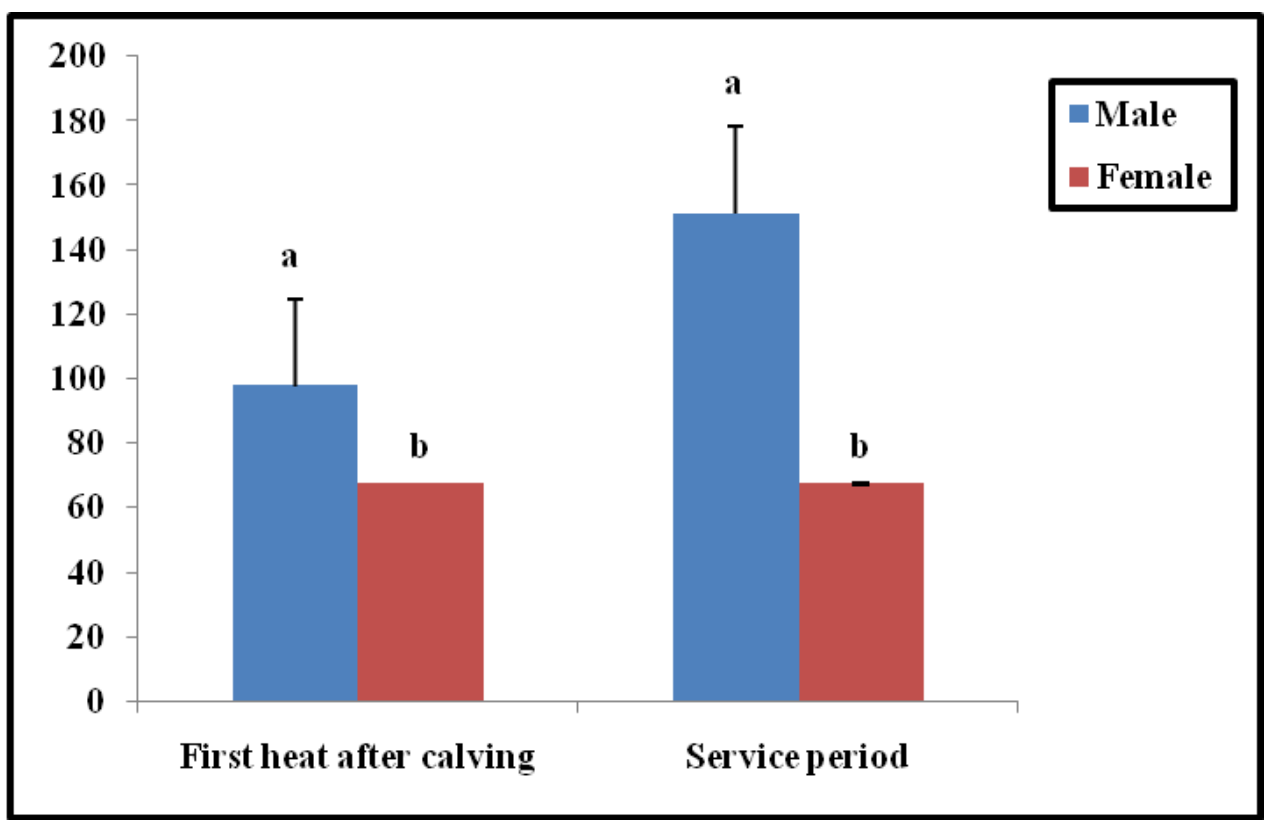

Fig.2 First heat after calving and service period of dam of suckled and weaned buffalo calves

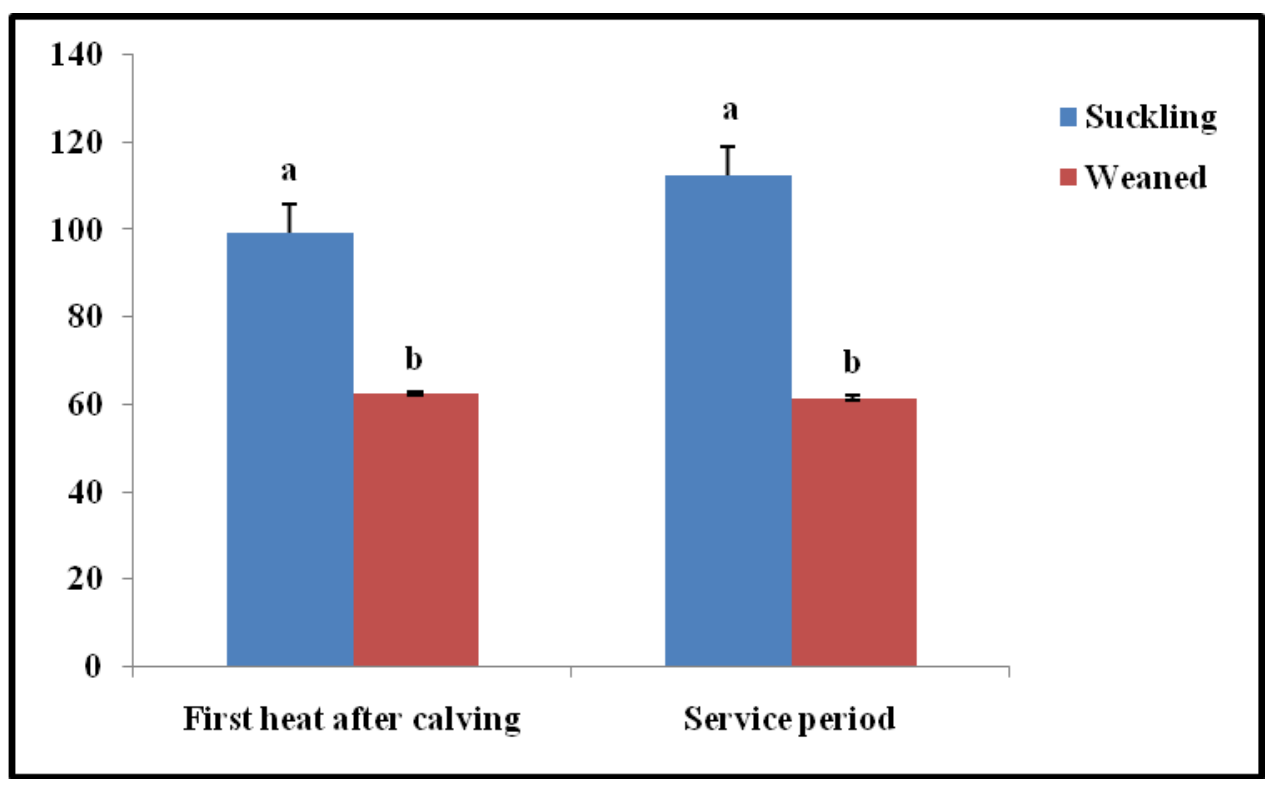


The present finding that weaned buffaloes resumed behavioural estrus significantly earlier possibly indicated towards a rapid response of these animals to LH release. Significantly prolonged interval to first postpartum ovulation only when the cow receives an adequate stimuli from her own calf or from an unrelated calf to which she has bonding (Stevenson et al., 1997). Margerison et al., (2002) reported that cows suckled by their own calves had a longer interval from calving to first oestrus than the cows suckled by other calves. The bond between the dam and the offspring is established through complex mechanisms that include visual, sensory and olfactory cues (Stevenson et al., 1997). Weaning calves during the first week after calving dramatically reduces the time from calving to the onset of ovarian activity (Wells et al., 1985). However, the effect of weaning calves beyond the first week after calving resulted in varied responses (Lishman and Harwin, 1985). Early weaning is effective in removing the suppressive effects of suckling from the hypothalamohypophyseal-gonadal axis (Bell et al., 1998). Weaning after day 45 postpartum, when the suppressive effect of suckling is diminished, it did not affect the duration of postpartum anoestrus (Yavas and Walto, 2000). Weaning by day 60 or 90 did not improve postpartum fertility (Qureshi and Ahmad, 2008).

Dams of suckling calves had more mean for service period than dams of weaned calves and it was found to be almost double of that of dams of female calves. Similar reports were presented by Sikka et al., (2000) where service period was reduced by 72 days in dams of weaned buffalo calves as compared to their suckling counterparts. And, this was also in agreement with the reports of Jainudeen (1988) who suggested that weaning reduced the incidence of postpartum anoestrus. The report of Montiel and Ahuja (2005) supported this fact in Bos indicus cows too who concluded that early weaning increased pregnancy rates in some herds, but response varied widely. This was further supported by the reports of Abeygunawardena et al., (1995) who reported that suckling ad libitum in buffaloes resulted in lower conception rates. In contrary to present finding, Bell et al., (1998) reported that early weaning did not affect the postpartum interval to pregnancy or pregnancy rate. It was concluded that dam of male calve have long period of first heat after calving and service period than dam of female buffalo calve. Similarly, dam of suckled have long period of first heat after calving and service period than dam of weaned buffalo calve.

\section{References}

Lamb, G. C., Lynch, J. M., Grieger, D. M., Minton, J. E. and Stevenson, J. S., 1997. Ad libitum suckling by unrelated calves in the presence or absence of a cow's own calves prolongs postpartum anovulation. Journal of Animal Science, 75:2762.

Lamb, G. C., Miller, B. L., Lynch, J. M., Thompson, K. E., Heldt, J. S., Loest, C. A., Grieger, D. M. and Stevenson, J. S. 1999. Twice daily suckling but not milking with calves presence prolongs postpartum anovulation. Journal of Animal Science, 77:2207.

Rae, D. O., Kunkle, W. E., Chenoweth, P. J., Sand, R. S. and Tran, T., 1993. Relationship of parity and body condition score to pregnancy rates in Florida beef cattle. Theriogenology 39:1143.

Short, R. E., Bellows, R. A., Staigmiller, R. B., Berardinelli, J. G. and Custer, E. E., 1990., Physiological mechanisms controlling anestrus and infertility in postpartum beef cattle. Journal of Animal Science 68:799.

\section{How to cite this article:}

Kantharaja, K.J., A.K.S. Tomar, O.R. Nataraju and Naveen Kumar, B.T. 2018. Effects of Weaning and Sex of Calf on Postpartum Resumption of Reproduction in Mother Buffaloes. Int.J.Curr.Microbiol.App.Sci. 7(05): 734-737. doi: https://doi.org/10.20546/ijcmas.2018.705.088 